\title{
Case Report: Effects of Motor Control Training on the Concept of Kinetic Control in Treating Patella Ligament Tendinopathy in a Female Football Player
}

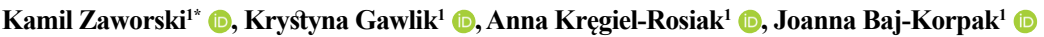

1. Department of Physiotherapy, Pope John Paul II State School of Higher Education, Biała Podlaska, Poland.

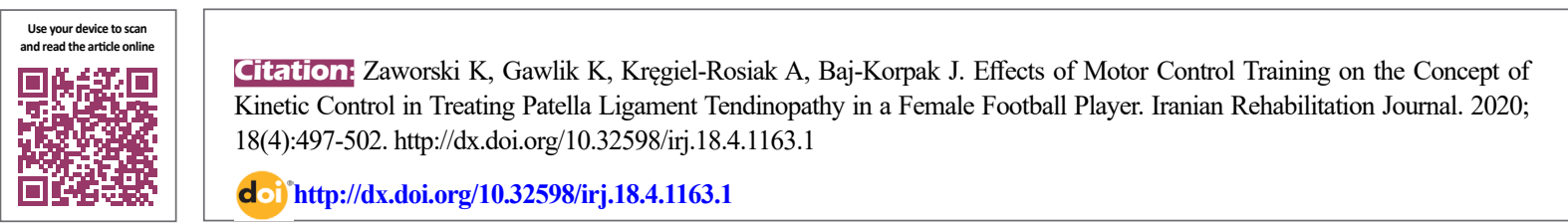

Article info:

Received: 27 Jun 2020

Accepted: 04 Dec 2020

Available Online: 01 Dec 2020

Keywords:

Knee, Patella, Tendinopathy, Exercise therapy

\section{ABSTRACT}

Objectives: Patellar ligament tendinopathy, also known as jumper's knee, is a group of pain symptoms of the anterior side of the knee joint. The Kinetic Control (KC) concept uses the movement control rating system, based on motor tests and exercises aimed at re-educating motor control. The present study explored the effects of motor control training on the $\mathrm{KC}$ concept in treating patella ligament tendinopathy in a female football player.

Methods: The current case study was conducted on a 20 -year-old female football player. She had been complaining of pain in the front of the right knee joint for two months. Her treatment involved $\mathrm{KC}$ training was conducted for 6 weeks ( 3 times a week for 30 minutes). To investigate the effectiveness of the presented therapy, the following tools were used: Visual Analogue Scale (VAS), The Victorian Institute of Sport Assessment-Patella (VISA-P scale), the Modified Laitinen Pain Questionnaire, Counter Movement Jump (CMJ) test on a dynamometric platform, and quadriceps muscle isometric test. The Asymmetry Index (AI) was applied to assess the asymmetry of quadriceps strength and lower limb loading.

Results: The degree of pain (i.e. measured by the VAS) decreased from 7 points at pre-training to 1 point after 6 weeks of therapy. In the VISA-P measurement, pain decreased as a result of an increase in points from 53 to 82. Pain complaints (i.e. measured using the Laitinen questionnaire) decreased from 7 to 2 points. After treatment, the AI improved in all phases of the tests.

Discussion: The achieved data indicated that the neuromuscular $\mathrm{KC}$ training was effective in treating patellar tendinopathy. However, it is necessary to conduct further studies with larger sample size. 


\section{Highlights}

- Patella ligament tendinopathy is a common problem among professional athletes.

- Kinetic Control uses the Movement Control Rating System based on motor tests, the purpose of which is to identify the place and direction of uncontrolled movements and exercises to re-educate motor control.

- The neuromuscular training following the Kinetic Control concept is effective in the treatment of patellar tendinopathy.

\section{Plain Language Summary}

Patellar ligament tendinopathy, also known as jumper's knee, is a group of pain symptoms of the anterior side of the knee joint. The aim of the article is to present the effectiveness of motor control training in the Kinetic Control concept in the treatment of patella ligament tendinopathy in a female football player. The Kinetic Control concept uses the Movement Control Rating System, based on motor tests and exercises aimed at re-educating motor control. The case study concerned a female patient (20 years old) who was a soccer player. Her treatment involved training in the Kinetic Control concept conducted for a period of 6 weeks. In order to verify whether the therapy was effective, the following were used: Visual Analogue Scale (VAS), The Victorian Institute of Sport Assessment-Patella (VISA-P) scale, Modified Laitinen Pain Questionnaire, Counter Movement Jump (CMJ) test on a dynamometric platform and quadriceps muscle isometric test. The asymmetry index (AI) was used in order to assess the asymmetry of quadriceps strength and limb loading lower ones. After the end of the treatment, a decrease in pain and an improvement in the asymmetry index were noted. The results achieved indicate that the neuromuscular training following the Kinetic Control concept is effective in the treatment of patellar tendinopathy. However, it is necessary to conduct further studies with a larger group of subjects.

\section{Introduction}

atellar ligament tendinopathy, referred to as “jumper's knee", is a set of pain symptoms of the anterior side of the knee joint.

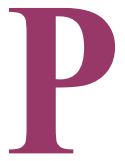
An advanced disease entity can indicate the end of a sports career [1]

It is estimated that patella ligament tendinopathy occurs in approximately $15 \%$ of professional athletes [2]. Clinical observations suggested multiple microtraumas caused by (among others excessive load) excessive training time, bad ground, and training errors to be its external causes $[1,3]$. Internal causes are not fully understood [4].

As per the literature, eccentric and heavy slow resistance exercises are among the most effective methods of treating patella tendinopathy. Such passive interventions as ultrasound or techniques of manual therapy aim at decreasing pain; however, their effect is short-lived [3].

The Kinetic Control (KC) concept uses the movement control rating system based on motor tests; the purpose of which is to identify the place and direction of uncontrolled movements and exercises to re-educate motor control [5]. The lack of control of internal rotation in the hip joint and the proper positioning of the pelvis during movement may lead to overloading the patella ligament $[6,7]$. The present study explored the effects of motor control training in the $\mathrm{KC}$ concept on treating patella ligament tendinopathy in a female football player.

\section{Case Presentation}

The participant was a 20-year-old female football player of the AZS-PSW Biała Podlaska Sports Club (weight: $62 \mathrm{~kg}$, height: $167 \mathrm{~cm}$, body mass index: $22.23 \mathrm{~kg} / \mathrm{m}^{2}$ ). Besides, she had played at the right aid position for 3 years. She had been complaining of pain in the front of the right knee joint for two months. Initially, pain occurred after 30 minutes of training/playing. Moreover, on the day of treatment onset, pain occurred even when getting up from the chair after sitting for a long time and immediately after undertaking the physical effort.

Accordingly, we found no restriction in the range of movement of the affected knee, compared to the healthy $\operatorname{leg}\left(\mathrm{AROM}=125^{\circ}, \mathrm{PROM}=130^{\circ}\right.$; measurement was performed in a back lying position using a goniometer). The patient's patellar tendon was tender on palpation. The right lower limb was dominant. The patient provided written informed consent for participation in the study. The research was approved by the Bioethics Committee 
Table. 1. Exercises used in the KC training

\begin{tabular}{ccc}
\hline & Therapy \\
\hline Exercise & Description \\
\hline
\end{tabular}

Starting position: patient in standing position, lower limbs in a neutral position, with the spine correctly positioned.

Execution: The patient performs a quarter of a squat while controlling the neutral position of the lower limb - the line passing through the middle of the thigh should project to the second toe (the entire limb set at $8-10^{\circ}$ of external rotation). The torso should

Controlling flexion, adduction, and internal rotation in the hip joint

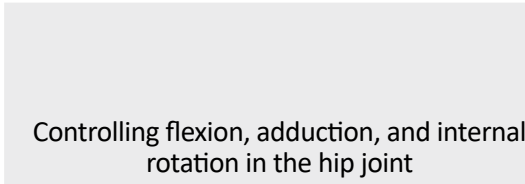

Strengthening the gluteus maximus muscle

Quadriceps thigh muscle stretching remain in a neutral position without any compensation from the lumbar region. To facilitate the task at the initial stage of therapy, the feedback was used in the form of a mirror and exercises performed while leaning the back against the wall. The number of repetitions: 3 sets, 10 repetitions.

Progression: +5 repetitions in the second, fourths, and sixth weeks of the training.

Starting position: the patient in a standing position with the lower limb trained in a step forward. Thera-band tape is used around the knee joint, perpendicular to the long axis of the limb from the medial side.

Execution: The patient performs an orbital squat, with the control of the neutral position of the lumbar spine and the axis of both the forward limb and the backward limb. Note the torso position. The knee of the forward leg should not exceed the foot line. The number of repetitions: 3 sets, 10 repetitions.

Progression: +5 repetitions in the second, fourths, and sixth weeks of the training.

Starting position: lying forward on the edge of a couch, the lower limb (exercising) bent in the hip and knee joint $\left(90^{\circ}\right)$ with the foot behind the second knee.

Execution: raising the lower limb bent at the knee $\left(90^{\circ}\right)$ in a controlled range of motion and maintaining the final position for 10 seconds.

The number of repetitions: 3 sets of 10 repetitions.

Progression: +5 repetitions in the second, fourths, fifth and sixth week of the training.

Initial position: kneeling on one leg on the lower limb which will be stretched. Keeping the neutral position of the lumbar spine, the patient grips the foot of the extended limb with the hand and pulls it to the buttock.

Execution: 7-10 seconds of quadriceps muscle tension in the direction of extension in the knee joint, after which the patient deepens the flexion with a hand holding for 10 seconds.

The number of repetitions: 1 series, 10 repetitions.

Progression: +5 repetitions in the third week of the training.

Mranian Rehabilitation Journa

of the Pope John Paul II State School of Higher Education in Biała Podlaska (No. 3/2018).

The 6-week treatment program was implemented for motor control training in the concept of $\mathrm{KC}$. The training was performed in 6 weeks, and 3 times a week for 30 minutes. During the first training, functional tests of both limbs were conducted and an individual exercise plan was developed. The functional tests [5-7] were performed before initiating treatment. The relevant data reported disturbances of flexion, adduction, and external rotation in the hip joint, the shortening of the thigh's quadriceps muscle, and the weakness of the group of external thigh rotators on the right side. Four exercises were used in the therapy; the purpose of which was reeducating lower limb movement control, the concentric and eccentric work of the quadriceps muscles of the thigh and the group of external thigh rotators, and stretching the quadriceps muscle of the thigh (Table 1).
To evaluate the effects of the provided treatment, the following tools were used: Visual Analogue Scale (VAS) scale: the subjective assessment of the severity of the pain; VISA-P scale: the subjective assessment of pain in athletes suffering from patellar tendinopathy [3]; Modified Laitinen Pain Questionnaire: the assessment of the pain level and the number of episodes in patients, the use of painkillers, and the extent to which the motor activity was limited [8] CMJ test on a dynamometric platform: the ground reaction force was measured on a GAMMA dynamometric platform (AC International East) using VAST software. The lower limb load was assessed by a vertical test with arm swing. The jump methodology described by Bell et al. [9] was also used. In the analysis of the lower limb load distribution, two test phases were considered; the rebound phase and the landing phase.

Quadriceps muscle isometric test: the strength of the isometric contraction of the quadriceps $(\mathrm{Nm})$ was measured using a Sumer II dynamometric chair (UPR-01B). The test 
Table 2. Values of the asymmetry index in tests performed before and after the treatment

\begin{tabular}{cccccccc}
\hline Measurement & \multicolumn{3}{c}{ Pre-Treatment } & \multicolumn{3}{c}{ After A 6-Week Treatment } \\
\hline CMJ & Right Leg (kg) & Left Leg (kg) & Al (\%) & Right leg (kg) & Left leg (kg) & Al \\
\hline CMJ - rebound phase & 83 & 94 & $-12,43$ & 91 & 95 & $-4,3$ \\
CMJ - landing phase & 108 & 133 & $-20,75$ & 119 & 126 & $-5,71$ \\
\hline Measuring force in isometric contraction & Right leg (Nm) & Left leg (Nm) & Al & Right leg (Nm) & Left leg (Nm) & Al \\
Quadriceps femoris muscle & 127 & 143 & $-11,85$ & 155 & 148 & 2 \\
\hline
\end{tabular}

methodology proposed by Daneshjoo et al. [10] was used in this regard. The strength of the isometric contraction of the quadriceps muscle was measured at the $90^{\circ}$ flexion of the knee joint. In the analysis of the lower limb load distribution, two test phases were considered; the rebound phase and the landing phase.

The Asymmetry Index (AI) was used $[9,11]$ to assess the asymmetry of quadriceps strength and limb loading lower ones. Having completed the Kinetic Control therapy therapy, the obtained results were established as the standard in all functional tests.

The degree of pain measured using the VAS scale decreased from 7 points at pre-training to 1 point after 6 weeks of therapy. In the VISA-P measurement, pain decreased as a result of an increase in points from 53 to 82. Pain complaints measured using the Laitinen questionnaire decreased from 7 to 2 points. After the completion of the treatment, the AI improved in all test phases. The related detailed data are presented in Table 2. Following the treatment completion, no tenderness on palpation was noted in the patellar tendon.

\section{Discussion}

In the conservative treatment of tendinopathy, patellar ligaments, including pharmacotherapy, physical therapy, and kinesiotherapy are implemented. The most studied and recommended training method involves eccentric exercises [3].

The training in the $\mathrm{KC}$ concept used in the above case study also applied the eccentric phase of quadriceps muscle contraction. Furthermore, the functional test included in the method allows identifying movement control disorders that cause the overloading of certain structures and the formation of tendinopathy and develop an individual exercise plan. Improving the motor control of external rotation and adduction in the hip joint; thus, reducing the external rotation of the lower leg allows reducing forces influencing the patella ligament under dynamic conditions [7].
In the presented case study, motor control training in the $\mathrm{KC}$ concept positively affected the reduction of pain measured by the Visual Analogue Scale (VAS) scale, The Victorian Institute of Sport Assessment-Patella (VISA-P), and the Laitinen questionnaire in a patient with patella ligament tendinopathy. The pre-treatment results of the VISA-P scale equaled 53 points, i.e. consistent with the data presented by Zwerver and associates. The authors argued that the average result in patients with patellar ligament tendinopathy was obtained as 58.2 points [12].

Football is a discipline in which players usually present further load on the dominant lower limb. Consequently, the limbs' asymmetry is manifested in the structure of the musculoskeletal system as well as the associated difference in muscle strength and endurance [13]. Some authors also indicated that an asymmetry above $10 \%-15 \%$ could be an indicator of future injury [14].

We assessed the AI in the vertical jump test with arm swing and the isometric strength of the quadriceps muscles before initiating the therapy. Accordingly, we observed a disturbance of load distribution and isometric strength of the lower limbs with a higher load and strength of the healthy lower limb. After the therapy, the AI was improved, which could be due to decreased pain. These observations were in line with those of Rosen et al. who signified the relationship between pain and dynamic postural control in patients with patellar tendinopathy [15].

According to the authors, a constraint of their study was the lack of evaluating the athlete's motor ability and analyzing the biomechanical parameters of gait. Following the completion of treatment, the athlete continued her training regime full time.

Lederman described a model that can be used to evaluate motor control, based on the following characteristics: speed, force, endurance, range (forming a parametric group of capabilities), reciprocal activation, and simultaneous contraction forming a group of synergistic abili- 
ties, and the composite motor capabilities of much more complex nature, including motor relaxation, balance, coordination, and transition time separating various activities [16]. In their study, the authors used 4 exercises focused on controlling the movement of the hip joint and the strength of the gluteal group muscles and the quadriceps.

\section{Conclusion}

No research on this problem, and consequently, no comparative possibilities for research was a limitation of the study. Demonstrating the effects of motor control training in the concept of $\mathrm{KC}$ in treating the tendinopathy of the patella ligament in football players encourages further extensive research in this field on a larger sample of female players.

\section{Ethical Considerations}

\section{Compliance with ethical guidelines}

The research was approved by the Bioethics Committee of the Pope John Paul II State, School of Higher Education in Biała Podlaska (No. 3/2018).

\section{Funding}

This study was funded by the Pope John Paul II State School of Higher Education in Biała Podlaska, Poland (Grant No. S/8/2018).

\section{Authors' contributions}

Conceptualization: Kamil Zaworski; Methodology: Kamil Zaworski, Krystyna Gawlik; Investigation: Kamil Zaworski, Anna Kręgiel-Rosiak; Writing - original draft: Kamil Zaworski, Krystyna Gawlik, Anna KręgielRosiak; Writing - review \& editing: Kamil Zaworski, Joanna Baj-Korpak; Funding acquisition, resources: All authors; Supervision: Kamil Zaworski, Krystyna Gawlik, Joanna Baj-Korpak.

\section{Conflict of interest}

The authors declared no conflicts of interest.

\section{References}

[1] Nagraba Ł, Mitek T, Szulwic A, Zakrzewska M, Deszczyński JM. [Treatment of patients with jumper's knee syndrome, with a particular role of physiotherapy (Polish)]. Artroskopia i Chirurgia Stawów. 2011; 7(1-2):27-36. [DOI:10.5604/.949764]

[2] Tiemessen IJH, Kuijer PPFM, Hulshof CTJ, Frings-Dresen MHW. Risk factors for developing jumper's knee in sport and occupation: A review. BMC Research Notes. 2009; 2:127. [DOI:10.1186/1756-0500-2-127] [PMID] [PMCID]

[3] Malliaras P, Cook J, Purdam C, Rio E. Patellar tendinopathy: Clinical diagnosis, load management, and advice for challenging case presentations. Journal of Orthopaedic \& Sports Physical Therapy. 2015; 45(11):887-98. [DOI:10.2519/jospt.2015.5987] [PMID]

[4] Danielson P. Reviving the ,'biochemical' hypothesis for tendinopathy: New findings suggest the involvement of locally produced signal substances. British Journal of Sports Medicine. 2009; 43(4):265-8. [DOI:10.1136/bjsm.2008.054593] [PMID]

[5] Comeford M, Mottram S. Kinetic Control. The Management of Uncontrolled Movement. London: Churchill Livingstone Australia; 2012. https://www.amazon.com/Kinetic-ControlManagement-Uncontrolled-Movement/dp/0729541673

[6] Gryckiewicz S, Hadała M. [Eccentric failure of the average gluteus muscle as a frequent cause of knee injuries in sport based on kinetic control (Polish)]. Praktyczna Fizjoterapia \& Rehabilitacja. 2012; 34:58-63. https://movement-system. $\mathrm{pl} /$ pobierz/ekscentryczna-niewydolnosc-miesnia-posladkowego-sredniego-jako-czesta-przyczyna-urazow-stawukolanowego-w-sporcie-na-podstawie-kinetic-control/

[7] Worobel M, Gniewek T, Hadała M. [Training of motor control in lateral patella support according to the Kinetic Control concept - case report. Part I. Global work (Polish)]. Praktyczna Fizjoterapia \& Rehabilitacja. 2013; 42:6-12.

[8] Czenczek-Lewandowska E, Przysada G, Brotoń K, Leszczak J, Rykała J, Podgórska-Bednarz J. [Impact of rehabilitation on the functional state and pain of patients with spinal overload syndrome (Polish)]. Przegląd Medyczny Uniwersytetu Rzeszowskiego i Narodowego Instytutu Leków w Warszawie 2014; 3:243-52. http://yadda.icm.edu.pl/yadda/element/ bwmeta1.element.desklight-a85f52b5-6820-4f72-8353-fc3acc3234fc

[9] Bell DR, Sanfilippo JL, Binkley N, Heiderscheit BC. Lean mass asymmetry influences force and power asymmetry during jumping in collegiate athletes. Journal of Strength and Conditioning Research. 2014; 28(4):884-891. [DOI:10.1519/ JSC.0000000000000367]

[10] Daneshjoo A, Rahnama N, Mokhtar AH, Yusof A. Effectiveness of injury prevention programs on developing quadriceps and hamstrings strength of young male professional soccer players. Journal of Human Kinetics. 2013; 39(1):115-25. [DOI:10.2478/hukin-2013-0074]

[11] Rutkowska-Kucharska A. Asymmetry of lower limb strength and jumping ability of young soccer players. Acta of Bioengineering and Biomechanics. 2020; 22(1):79-85 [DOI:10.37190/ABB-01513-2019-03] [PMID]

[12] Zwerver J, Kramer T, van den Akker-Scheek I. Validity and reliability of the Dutch translation of the VISA-P questionnaire for patellar tendinopathy. BMC Musculoskelet Disord. 2009; 10:102. [DOI:10.1186/1471-2474-10-102] [PMID] [PMCID]

[13] Hart NH, Nimphius S, Spiteri T, Newton RU. Leg strength and lean mass symmetry influences kicking performance in 
Australian football. Journal of Sports Science \& Medicine. 2014; 13(1):157-65. [PMCID]

[14] Rodríguez-Lorenzo L, Fernández-Del Olmo M, SánchezMolin JA, Martín-Acero R. Kicking ability and kicking deficit in young elite soccer players. Kinesiology. 2018; 50(2):194-203. [DOI:10.26582/k.50.2.2]

[15] Rosen AB, Ko J, Brown CN. The relationship between acute pain and dynamic postural stability indices in individuals with patellar tendinopathy. Gait \& Posture 2018; 65:117-20. [DOI:10.1016/j.gaitpost.2018.07.003] [PMID]

[16] Lederman E. The myth of core stability. Journal of Bodywork and Movement Therapies. 2010; 14(1):84-98. [DOI:10.1016/j.jbmt.2009.08.001] [PMID] 